\title{
Are hearing loss and balance dysfunction linked in construction iron workers?
}

\author{
Kaye H Kilburn, Raphael H Warshaw, Brad Hanscom
}

\begin{abstract}
The objective was to determine whether an association existed between hearing loss and balance dysfunction in construction workers exposed to noise. Screening pure tone audiometry and balance testing were performed using a sound emitter and dual microphone system to evaluate 78 iron workers who were compared with 128 histology technicians. Most ironworkers showed hearing loss at frequencies below $3000 \mathrm{~Hz}$. Their sway speeds were significantly faster both with the eyes open $(1.05($ SD 0.39) $v 0.91($ SD 0.22$) \mathrm{cm} / \mathrm{s})$ and with eyes closed (1.66 (SD 0.82) $v 1.31$ (SD 0.51) $\mathrm{cm} / \mathrm{s}$ ) than those of histology technicians. Coefficients for sway speed with the eyes closed and hearing loss in the left ear were significantly correlated at 500 to $8000 \mathrm{~Hz}$. They were also correlated with the sway speed, eyes open, at low and high Hz. It is concluded that the use of air impact power tools in an inordinately noisy work environment makes iron workers prematurely deaf and impairs their balance. Falls may be related to balance dysfunction and impaired equilibrium. Falls from height injure and kill iron workers. Further investigations will determine whether injuries from falls are linked to these impairments.
\end{abstract}

While examining iron workers for signs of asbestosis and pulmonary disease it was noted that many wore hearing aids and that some showed evidence of past musculoskeletal or head injuries. These findings led to inquiries about their frequency of hearing loss and of falls at work, prevalences that exceeded those for other construction workers. Because body sway was shown to be excessive in men in military service who had noise induced damage on audiometric testing ${ }^{1}$ we

University of Southern California School of Medicine, Environmental Sciences Laboratory, 2025 Zonal Ave, RB-1 Room 226, Los Angeles, CA 90033, USA

Kaye H Kilburn, Raphael H Warshaw, Brad Hanscom asked the question: Is hearing loss related to defective balance as measured by increased speed of postural sway? We inferred that defective balance may cause iron workers to fall and be injured. Balance with the eyes closed tests proprioception, vestibular apparatus, the cerebellum, and effectors of trunk fixation. With the eyes open, visual effector links contribute to stability of balance. To determine if hearing loss was related to defective balance, we carried out audiometry and tested balance in members of the iron workers' local union in whom our original observations had been made.

\section{Methods}

Iron workers from the St Louis iron workers' local union were invited for audiometry and balance testing. To survey the union members across a wide range of age, we invited apprentices to participate as well as journeymen who were active or retired, with up to 30 years of experience. The 78 men we tested were aged 22 to 79 (mean 53.3). Comparisons of body balance were made with 128 laboratory (histology) technicians (men and women) aged 26 to 69 (mean 44.2) who had been tested in a prospective study of neurobehavioural effects of formaldehyde and solvents. $^{23}$

Manual audiometry was carried out in a standard sound suppressed chamber on each ear separately. Hearing thresholds were determined at frequencies of $500,1000,2000,3000,4000,6000$, and $8000 \mathrm{~Hz}$. Audiometry was carried out after at least 18 hours away from noise exposure at work.

Balance was tested on an uncovered floor with subjects standing with eyes focused on a target. A sound emitting stylus was attached to the subject's head with a head band. Paired microphones were mounted parallel to the subject's right side $50 \mathrm{~cm}$ from the stylus and $46 \mathrm{~cm}$ apart. The pathway traced by the stylus and its speed were recorded on a microprocessor based controller that recorded position every $10 \mathrm{~ms}$ (Neuro-Test Inc No 355 Sheridan, Corona, CA 91720). Subjects were instructed to stand with feet pressed together and arms folded and to focus on a target six feet away while staying as still as possible for one minute. After a short rest period during which the subjects were encouraged to move 
Trial 1

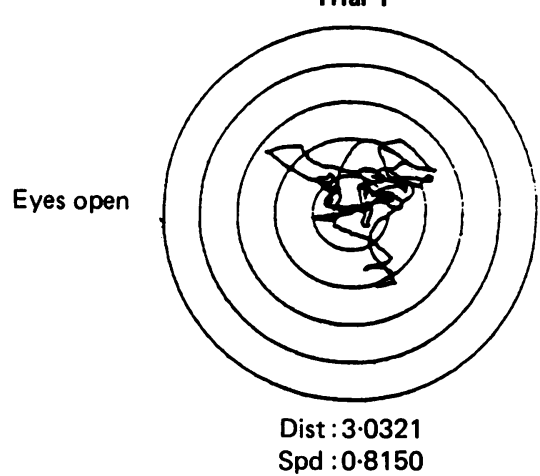

Spd : 0.8150

Eyes closed

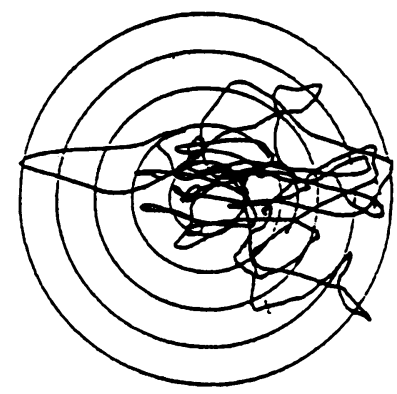

Dist : $7 \cdot 0083$

Spd : $2 \cdot 0026$
Trial 2
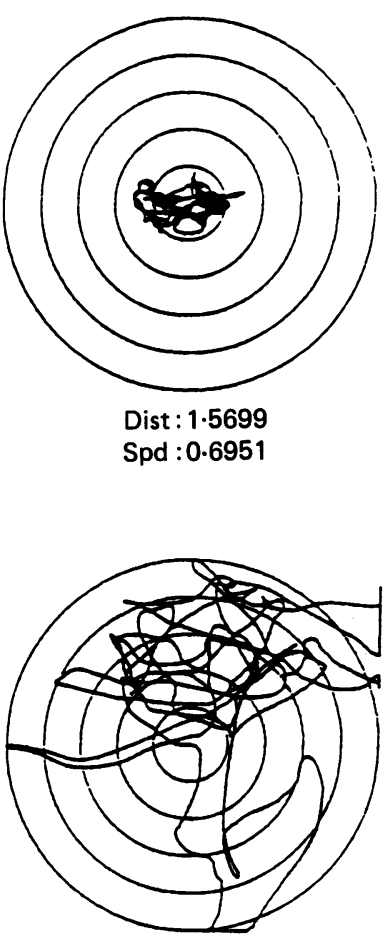

Dist : $6 \cdot 8123$

Spd : $2 \cdot 3251$
Trial 3

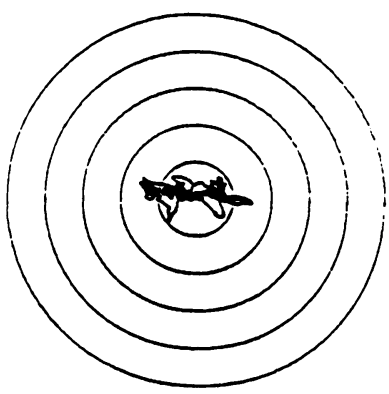

Dist : 1.4768

Spd : $0 \cdot 5619$

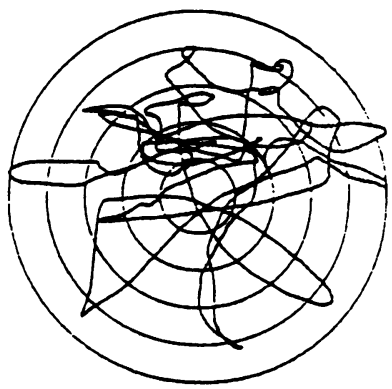

Dist : $6 \cdot 3852$

Spd : $2 \cdot 1024$

Copyright 1989 Neuro-test inc.

Normal pathways of sway in three trials with eyes open. The first, with a speed of $0.82 \mathrm{~cm} / \mathrm{s}$, is within a $3 \mathrm{~cm}$ circle and the second and third have decreased speeds and are within $2 \mathrm{~cm}$ circles. Abnormal paths are shown with eyes closed. These have abnormal speeds of $2 \cdot 0,2 \cdot 3$, and $2 \cdot 1 \mathrm{~cm} / \mathrm{s}$.

about, they were instructed to assume the same position, focus on the target, stand as still as possible, and then close their eyes for one minute. Sway was measured by the movement of the sound emitting stylus attached to the head relative to the pair of microphones so that the pathway traced by the stylus was recorded. The path of sway was printed on a diagram with $1 \mathrm{~cm}$ concentric circles (fig 1 ). Three sequences of sway with eyes open and three with eyes closed were recorded in each subject. Mean speed was the path length divided by seconds $(\mathrm{cm} / \mathrm{s})$. Sway data and results of other hearing tests were entered into a Compaq computer and analysed using Stata statistical programs (Computing Resource Center, Los Angeles, CA 90064) and Student's $t$ test for differences in means and linear regression analysis.

\section{Results}

Almost $25 \%$ of the iron workers had bilaterally equal hearing loss at $500 \mathrm{~Hz}$ that increased in prevalence at frequencies above $3000 \mathrm{~Hz}$ and reached $60 \%$ at the highest frequency of $8000 \mathrm{~Hz}$ (table 1). Although hearing losses were greatest in older men they were found in young men and across the age range.

Mean speed of sway with eyes open on the third one minute test was significantly faster in iron workers than in histology technicians (1.05 (SD 4.5) $v 0.91$ (SD 0.29); table 2). With eyes closed the speed of sway increased in both groups and again iron workers were significantly faster than were histology technicians. With eyes open, one minute recording periods were used in both groups and reproducibility was high; hence stability was apparently reached in the first one minute trial. With the eyes closed, histology technicians tended to improve from trial 1 to 3 whereas iron workers appeared to worsen slightly but these differences were not statistically significant. Again, as with sway speed with eyes open, stability appeared to have been reached in a one minute trial.

The coefficients of sway speed with eyes open and 
Table 1 Prevalence of hearing loss in 78 iron workers

\begin{tabular}{rll}
\hline & \multicolumn{2}{l}{ Prevalence } \\
\cline { 2 - 3 }$H z$ & Left ear $(\%(S D))$ & Right ear $(\%(S D))$ \\
\hline 500 & $23 \cdot 1(16 \cdot 8)$ & $23 \cdot 3(15 \cdot 3)$ \\
1000 & $24 \cdot 6(21 \cdot 1)$ & $25 \cdot 4(17 \cdot 8)$ \\
2000 & $33 \cdot 7(24 \cdot 1)$ & $34 \cdot 4(24 \cdot 1)$ \\
3000 & $50 \cdot 1(25 \cdot 9)$ & $47 \cdot 7(25 \cdot 8)$ \\
4000 & $58 \cdot 5(26 \cdot 6)$ & $59 \cdot 2(27 \cdot 3)$ \\
6000 & $61 \cdot 7(28 \cdot 0)$ & $62 \cdot 8(30 \cdot 4)$ \\
8000 & $59 \cdot 8(33 \cdot 9)$ & $61 \cdot 4(32 \cdot 6)$ \\
\hline
\end{tabular}

with eyes closed for hearing threshold in the left (most protected) ear showed significant correlations at low and high frequencies (table 3 ). These correlations with sway with eyes open were not significant in the mid-range but all correlations of hearing threshold and sway with eyes closed were statistically significant.

The age coefficient with balance speed with the eyes open was calculated by linear regression for iron workers. They showed a coefficient of 0.0144 , which was significant. Age explained $25.4 \%$ of the variance $\left(r^{2}\right.$; table 4). The findings for iron workers were similar with eyes closed, with $19.8 \%$ of the variance explained by age. Only the age coefficient for sway with eyes open was significant in the control group of histology technicians.

\section{Discussion}

This study showed that iron workers had hearing losses and balance deficits and that these abnormalities were highly correlated. Hearing and balance are functions of the auditory and vestibular divisions of the eighth cranial nerve. The correlation of deficits and the anatomy imply that noise damages the receptors of the eighth nerve to impair hearing and to impair balance. This correlation has been shown in soldiers exposed to high impulse noise from small arms and artillery fire in the Finnish Army. ${ }^{1}$ Iron workers represent an occupational group who are exposed to high levels of noise particularly from their

Table 2 Balance compared as speed of sway with eyes open and closed in iron workers and controls

\begin{tabular}{llll}
\hline & $\begin{array}{l}\text { Iron } \\
\text { workers }\end{array}$ & $\begin{array}{l}\text { Histology } \\
\text { technicians }\end{array}$ & pValue \\
\hline No & 78 & 128 & \\
Age (y (SD)) & $53.3(13.9)$ & $44.2(9.7)$ & 0.1 \\
Speed (cm/s (SD)): & $1.04(0.39)$ & $0.88(0.22)$ & 0.001 \\
Open 1 & $1.02(0.47)$ & $0.89(0.26)$ & 0.001 \\
Open 2 & $1.05(0.45)$ & $0.91(0.29)$ & 0.001 \\
Open 3 & $1.64(0.73)$ & $1.35(0.68)$ & 0.001 \\
Closed 1 & $1.61(0.75)$ & $1.30(0.54)$ & 0.001 \\
Closed 2 & $1.66(0.82)$ & $1.31(0.51)$ & 0.001 \\
Closed 3 & $1.66(0.8)$ \\
\hline
\end{tabular}

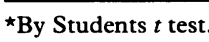

Table 3 Coefficients of balance speed and hearing threshold for the left ear in iron workers

\begin{tabular}{lll}
\hline Frequency & Eyes open & Eyes closed \\
\hline 500 & $0 \cdot 260$ & $0 \cdot 333$ \\
1000 & $0 \cdot 273$ & $0 \cdot 388$ \\
2000 & $0 \cdot 173$ (NS) & $0 \cdot 243$ \\
3000 & $0 \cdot 157$ (NS) & $0 \cdot 251$ \\
4000 & $0 \cdot 195$ (NS) & $0 \cdot 221$ \\
6000 & $0 \cdot 294$ & $0 \cdot 321$ \\
8000 & $0 \cdot 406$ & $0 \cdot 421$ \\
\hline
\end{tabular}

Statistically significant except (NS).

use of air impulse tools. Measurements of noise at enough work sites to represent average exposure are needed for dose-response calculations. Obviously many other occupations are heavily exposed to noise. Intuitively we would expect boilermakers, pipefitters, and operating engineers to have impairment because they are also heavily exposed to noise at work. All shipyard trades may share the problem because most make noise while working in close proximity and the noise is contained and reverberates within hulls and compartments.

Abnormality of balance in iron workers had a significant age coefficient and a relatively large proportion of the variance was accounted for by age. By contrast the age coefficient was much smaller with eyes open and not significant with eyes closed in the control group of medical laboratory workers. This control group resembles previous groups defined as normal in which balance has been unaffected by age except before age 10 and after age $70 .^{4}$ The age coefficient may be interpreted as evidence of the cumulative effect of years of excessive noise, in part because of the striking degree of accompanying hearing loss. It was also notable that even men in the apprentice programme, who were in their third decade and with less than three years of iron worker exposure, had hearing loss. If noise is responsible, thesefindings imply that effects are demonstrable after relatively brief exposures just as occurred in Finnish soldiers. ${ }^{1}$ This suggests that measures aimed at conserving hearing, which may also preserve balance function, must begin when entering the iron worker trade or earlier.

Table 4 Age coefficients for balance speed in iron workers and controls by linear regression

\begin{tabular}{lll}
\hline & Iron workers & Histology technicians \\
\hline Eyes open: & & \\
Coefficient & 0.0144 & 0.0067 \\
p Value & 0.000 & 0.000 \\
$\mathrm{r}^{2}$ & 0.254 & 0.098 \\
Eyes closed: & & \\
Coefficient & 0.0239 & 0.0070 \\
p Value & 0.000 & 0.189 \\
$\mathrm{r}^{2}$ & 0.198 & 0.006 \\
\hline
\end{tabular}


That hearing diminishes with age, especially at high frequencies, has been known for many years. ${ }^{56}$ This suggests that the younger segment of our control group may have some hearing loss. Their ability to hear human conversation, however, and the absence of the use of hearing aids were consistent with minor hearing impairment. On the other hand, many older iron workers wore hearing aids and interviewing them was difficult because of their impaired hearing. They portray the usual course of noise induced hearing loss. ${ }^{7}$ For balance or control of sway to show age deterioration before age 75 or 80 is unusual. ${ }^{4}$ Balance seems to develop rapidly between ages 6 to 9 and remains intact until the eighth decade. Studies of senior army officers with a long history of exposure to impulse noise from firearms showed noise induced hearing loss and balance dysfunction. ${ }^{8}$ Many of these men had had dizziness and spinning vertigo resembling Ménière's disease and the mechanism was postulated as delayed endolymphatic hydrops. Cochlear damage has been produced in experimental animals by acoustic overstimulation, extending even to complete disappearance of the organ of Corti. ${ }^{9}$ Damage to hearing has been associated recently with exposure to lead ${ }^{10}$ and toluene combined with noise has adverse effects on both hearing and balance. ${ }^{11}$ Other studies beginning nearly 50 years ago bave shown effects of ethyl alcohol on balance, which was detected in a similar manner to that used in the present study. ${ }^{12}$ Furthermore, xylene and alcohol were shown to have additive effects on impairing balance. ${ }^{13}$ These findings suggest that it will be important to check for possible confounding exposures before concluding that noise is solely responsible for defects in hearing and balance in construction or shipyard workers.

1 Juntunen J, Matikainen E, Ylikoski J, Ylikoski M, Ojala M, Vaheri E. Postural body sway and exposure to high-energy impulse noise. Lancet 1987;ii:261-3.

2 Kilburn KH, Seidman BC, Warshaw R. Neurobehavioural and respiratory symptoms of formaldehyde and xylene exposure in histology technicians. Arch Environ Health 1985;40:229-33.

3 Kilburn KH, Warshaw R. Formaldehyde impairs memory, equilibrium, and dexterity in histology technicians: effects which persist for days after exposure. Arch Environ Health 1987;42:117-20.

4 Sheldon JH. The effect of age on the control of sway. Gerontologica Clinica 1963;5:129-38.

5 Burns W, Robinson JW. Hearing and noise in industry. London HMSO, 1976.

6 Glorig A, Davis H. Age, noise and hearing loss. Ann Otol Rhinol Laryngol 1961;70:556-71.

7 Schneider EJ, Mutchler JF, Hoyle HR, Ode EH, Holder BB. The progression of hearing loss from industrial noise exposure. American Industrial Hygiene Association Journal 1970;31:368-76.

8 Ylikoski J. Delayed endolymphatic hydrops syndrome after heavy exposure to impulse noise. Am J Otol 1988;9:282-5.

9 Spoendlin H. Anatomical changes following various noise exposures. In: Henderson D, Hamernik RP, Dosanih DS, Mills JH, eds. Effects of noise on hearing. New York: Raven Press, 1976:69-87.

10 Schwartz J, Otto D. Lead and minor hearing impairment. Arch Environ Health 1991;46:228-35.

11 Morata TC, Dunn DE, Kretschmer LW, Lemasters GK, Santos UP. Effects of simultaneous exposure to noise and toluene on workers' hearing and balance. Archives of Complex Environmental Studies, 1991 (in press).

12 Goldberg L. Quantitative studies on alcohol tolerance in man. Acta Physiol Scand 1943;5:28-55.

13 Savolainen K. Combined effects of xylene and alcohol on the central nervous system. Acta Pharmacologica et Toxicologica $1980 ; 46: 366-72$.

Accepted 10 June 1991

\section{Correspondence and editorials}

The British Journal of Industrial Medicine welcomes correspondence relating to any of the material appearing in the journal. Results from preliminary or small scale studies may also be published in the correspondence column if this seems appropriate. Letters should be not more than 500 words in length and contain a minimum of references. Table and figures should be kept to an absolute minimum. Letters are accepted on the understanding that they may be subject to editorial revision and shortening.

The journal now also publishes editorials which are normally specially commissioned. The Editor welcomes suggestions regarding suitable topics; those wishing to submit an editorial, however, should do so only after discussion with the Editor. 